University of Nebraska - Lincoln

DigitalCommons@University of Nebraska - Lincoln

1978

\title{
Turbulent Exchange Coefficients for Sensible Heat and Water Vapor under Advective Conditions
}

\author{
Shashi Verma \\ University of Nebraska - Lincoln, cspinfo@unl.edu \\ Norman J. Rosenberg \\ University of Nebraska - Lincoln \\ Blaine L. Blad \\ University of Nebraska - Lincoln
}

Follow this and additional works at: https://digitalcommons.unl.edu/natrespapers

Part of the Natural Resources and Conservation Commons, Natural Resources Management and Policy Commons, and the Other Environmental Sciences Commons

Verma, Shashi; Rosenberg, Norman J.; and Blad, Blaine L., "Turbulent Exchange Coefficients for Sensible Heat and Water Vapor under Advective Conditions" (1978). Papers in Natural Resources. 1162.

https://digitalcommons.unl.edu/natrespapers/1162

This Article is brought to you for free and open access by the Natural Resources, School of at DigitalCommons@University of Nebraska - Lincoln. It has been accepted for inclusion in Papers in Natural Resources by an authorized administrator of DigitalCommons@University of Nebraska - Lincoln. 


\title{
Turbulent Exchange Coefficients for Sensible Heat and Water Vapor under Advective Conditions ${ }^{1}$
}

\author{
Shashi B. Verma, Norman |. Rosenberg and Blaine L. Blad ${ }^{2}$
}

(Manuscript received 18 April 1977, in final form 26 September 1977)

\begin{abstract}
Results are presented of micrometeorological measurements made over alfalfa and soybeans under conditions of sensible heat advection at Mead, Neb. The sensible heat advection phenomenon reported here is of a regional rather than a local nature. The exchange coefficient for sensible heat $\left(K_{H}\right)$ is found to be generally greater than the exchange coefficient for water vapor $\left(K_{W F}\right)$. This result contradicts the usual assumption of equality of $K_{\|}$and $K_{W}$ under nonadvection (lapse or unstable) conditions when the net transfer of both sensible heat and water vapor are away from the earth's surface. Under advective conditions, however, heat and water vapor are transferred in opposite directions. Our results are supported by Warhaft's (1976) recently published theoretical analysis in which he concludes that the greatest departure of $K_{H} / K_{W}$ from unity will occur when temperature and humidity gradients are of opposite sign.
\end{abstract}

\section{Introduction}

Reliable estimates of evapotranspiration are more difficult to obtain in semi-arid and sub-humid regions than in humid regions. In humid areas the evapotranspiration rate (at least the upper limit) is determined by the energy made available at the surface of the earth by the exchange of radiation (i.e., net radiation $R n$ ). In the east central Great Plains, a sub-humid region, evapotranspiration by well-watered crops frequently exceeds the energy content of $R n$ by a factor as great as 2 (Rosenberg, 1969). The additional energy is provided by the advection of sensible heat from arid regions which are primarily to the south and southwest. Occasionally, areas to the north are sources of warm, dry air as well.

Of the many available meteorological techniques for estimating evapotranspiration, the Bowen ratio-energy balance (BREB) method, has been widely used with reasonable accuracy under nonadvective conditions (Tanner, 1960; Pruitt and Lourence, 1968; Denmead and McIlroy, 1970). In eastern Nebraska under advective conditions we find, however, that the BREB method consistently underestimates lysimetrically measured values of evapotranspiration from well-watered alfalfa by about 20-30\% (Figs. 1 and 2). These results agree with findings of Blad and Rosenberg (1974) with

\footnotetext{
' Published as Paper No. 5319, Journal Series, Nebraska Agricultural Experiment Station. The work reported was conducted under Nebraska Agricultural Experiment Station Project 20-31 and Regional Research Project 11-33.

${ }^{2}$ Assistant Professor, Professor and Associate Professor, Agricultural Meteorology Section, Department of Agricultural Engineering, Institute of Agriculture and Natural Resources, University of Nebraska, Lincoln 68583.

$\overline{0021-8952 / 78 / 0330-0338 \$ 05.00}$

(C) 1978 American Meteorological Society
}

irrigated soybeans and with earlier findings (Rosenberg, 1969). Blad and Rosenberg (1974) explain that the underestimation of evapotranspiration by the BREB method, in their location, results from regional advection and not from factors associated with local advection due to insufficient fetch. ${ }^{3}$ That the occurrences of sensible heat advection reported here were also primarily regional in nature will be shown below.

The BREB method is described by

$$
L E_{\mathrm{BR}}=\frac{-(R n+S)}{1+\left(\frac{c_{p} P}{L_{\epsilon}}\right)\left(\frac{K_{H}}{K_{W}}\right)\left(\frac{\partial T / \partial z}{\partial e / \partial z}\right)}=\frac{-(R n+S)}{1+\beta},
$$

where

$$
\beta=\frac{A}{L E}=\frac{c_{p} P}{L_{\epsilon}}\left(\frac{K_{I I}}{K_{W}}\right)\left(\frac{\partial T / \partial z}{\partial e / \partial z}\right)
$$

is the Bowen ratio, and $A, L E_{\mathrm{BR}}, R n$ and $S$ are the flux densities of sensible heat, latent heat, net radiation and soil heat, respectively; ${ }^{4} L$ is the latent heat of vaporization, $E$ the water vapor flux, $c_{p}$ the specific heat of air at constant pressure, $P$ atmospheric pressure, $\epsilon$ the ratio of molecular weights of water $\left(M_{n}\right)$ to dry air $\left(M_{a}\right) ; K_{I I}$ and $K_{W}$ are the turbulent exchange coefficients for sensible heat and water vapor; and $\partial T / \partial z$

\footnotetext{
- Local and regional sensible heat advection has been studied by several workers, e.g. Sutton (1953), Philip (1959), Dyer (1963), Rider et al. (1963), McIlroy and Angus (1964), Rao et al. (1974).

- The sign convention employed here is such that all energy streams toward the crop or ground surface are positive and all away from the surface are negative.
} 
a
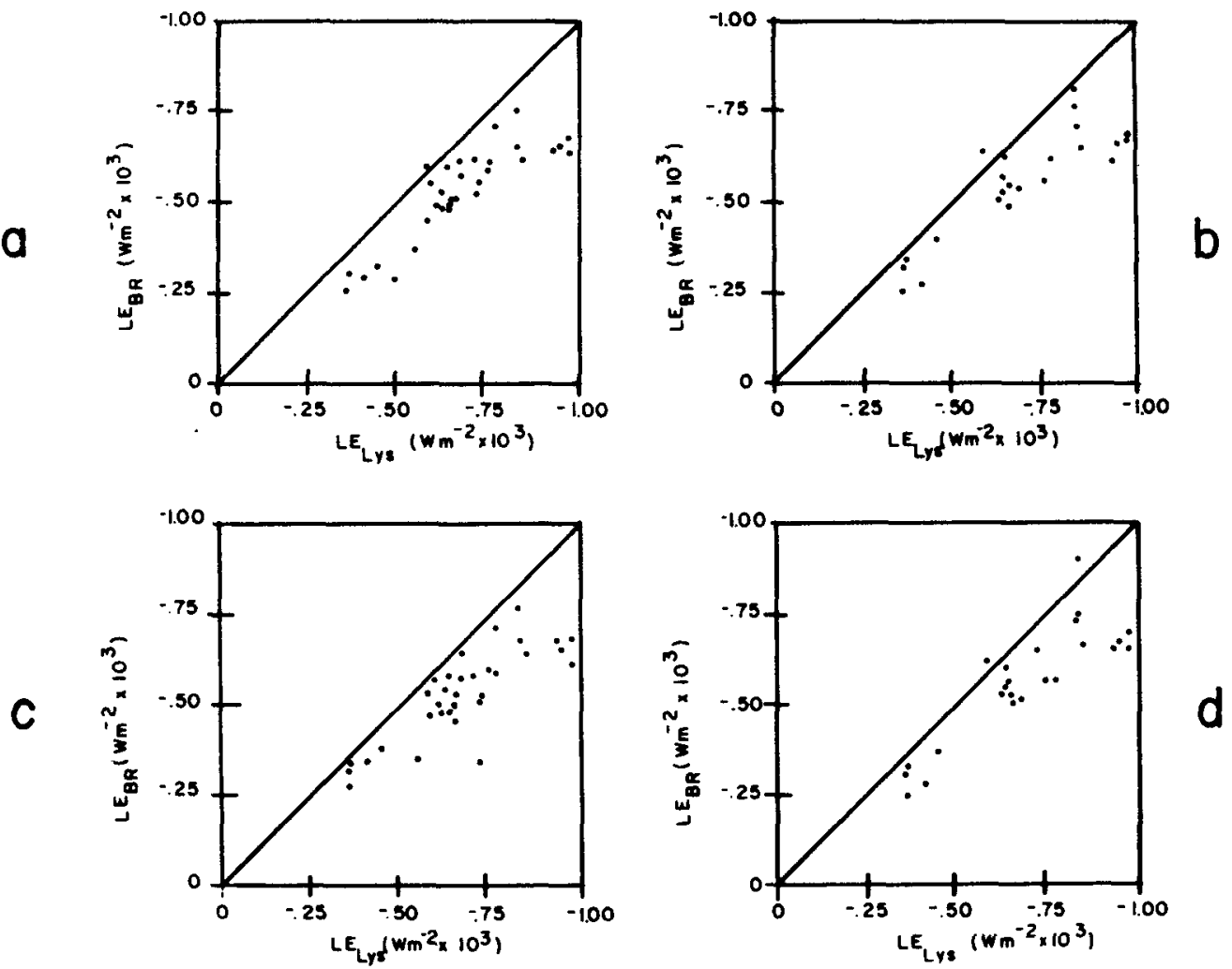

FIG. 1. BREB estimated $L E$ compared with lysimetrically measured $L E$ during Study 76-1 (5-22 June 1976) over alfalfa: (a) station 4, levels $1-2$; (b) station 5 , levels 1-2; (c) station 4, levels 1-3; (d) station 5 , levels 1-3. (Refer to Section 2 for details.)

and $\partial e / \partial z$ are gradients of air temperature and vapor pressure, respectively.

A basic assumption of the BREB method is the equality of exchange coefficients of $K_{I I}$ and $K_{W}$. Several previous investigations (e.g., Swinbank and

a

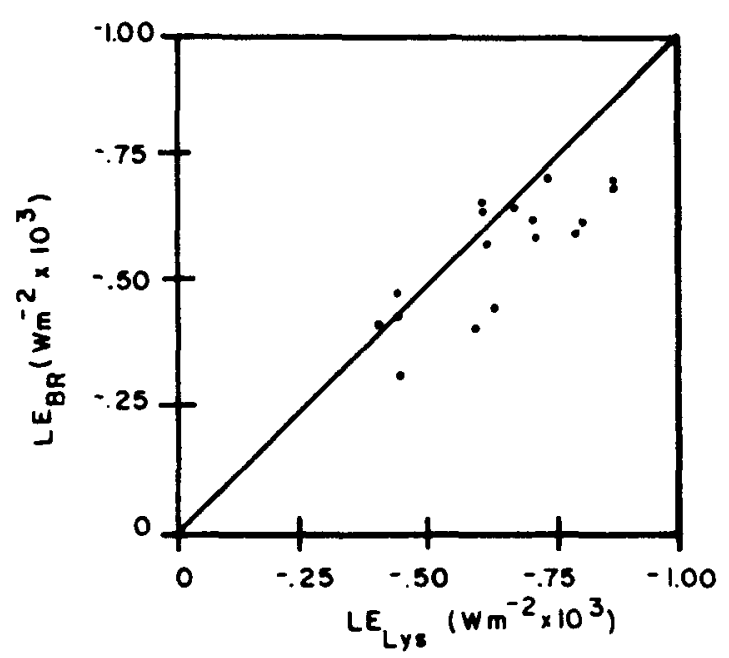

Dyer, 1967; Denmead and McIlroy, 1970) have presented evidence which supports this equality of $K_{H}$ and $K_{W}$ under nonadvective (lapse) conditions. Other investigators (e.g., Webb, 1970; Oke, 1970) have shown evidence of near equality of $K_{H}$ and $K_{W}$ under nocturna

b

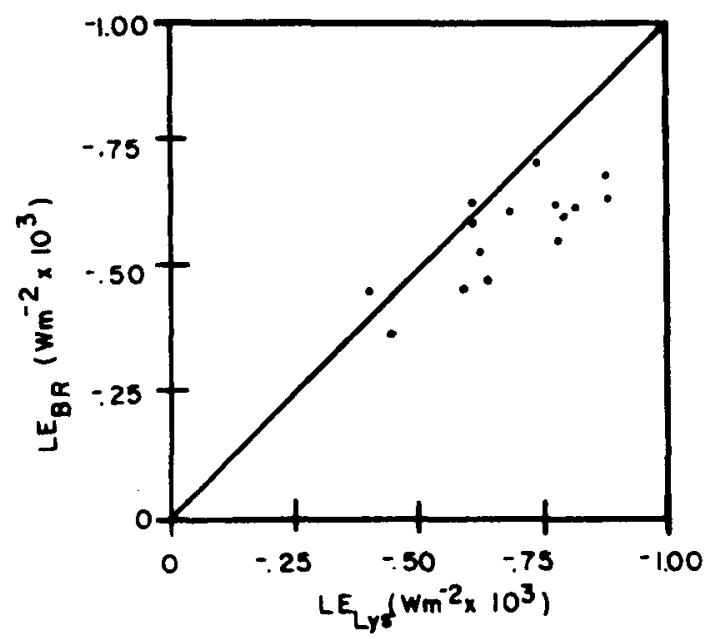

FIG. 2. BREB estimated $L E$ compared with lysimetrically measured $L E$ during study 76-2 (10 July-10 August 1976) over alfalfa: (a) station 5, levels 1-2; (b) station 5, levels 1-3. (Refer to Section 2 for details.) 
TABLE 1. Psychrometer elevation and crop height.

\begin{tabular}{|c|c|c|c|c|}
\hline Study & Level & \multicolumn{2}{|c|}{$\begin{array}{l}\text { Height above ground } \\
\text { (m) }\end{array}$} & $\begin{array}{l}\text { Crop height } \\
(\mathrm{m})\end{array}$ \\
\hline \multirow[b]{2}{*}{$76-1$} & & 5-10 June & 11-22 June & \multirow[b]{2}{*}{$0.32-0.43$ (5-10 June) } \\
\hline & $\begin{array}{l}1 \\
2 \\
3\end{array}$ & $\begin{array}{l}0.50 \\
0.75 \\
1.00\end{array}$ & $\begin{array}{l}0.75 \\
1.00 \\
1.25\end{array}$ & \\
\hline \multirow[b]{2}{*}{$76-2$} & & 10-22 July & 22 July-10 August & \multirow[b]{2}{*}{$0.19-0.45$ (10-22 July) } \\
\hline & $\begin{array}{l}1 \\
2 \\
3\end{array}$ & $\begin{array}{l}0.50 \\
0.75 \\
1.00\end{array}$ & $\begin{array}{l}0.75 \\
1.00 \\
1.25\end{array}$ & \\
\hline
\end{tabular}

inversion conditions. Blad and Rosenberg (1974), however, have questioned whether that assumption remains valid under advective conditions. In a recently published theoretical analysis of heat and moisture transport processes Warhaft (1976) concluded “. . . it appears that the causes for which the largest departure of $K_{H} / K_{W}$ from unity will occur are when either $T$ or $e$ is acting as a passive additive or when the temperature gradient is of opposite sign to the humidity gradient . . . ." Under advective conditions the temperature and humidity gradients are, indeed, of opposing sign. The objective of the research presented in this paper is to examine, experimentally, the $K_{H} / K_{W}$ ratio under conditions of sensible heat advection.

\section{Methods}

\section{a. Experimental details}

Measurements of micrometeorological parameters were made over well-watered alfalfa (Dawson cultivar, planted in spring 1975) at the University of Nebraska Agricultural Meteorology Laboratory at Mead $\left(41^{\circ} 09^{\prime}\right.$ $\mathrm{N}, 96^{\circ} 30^{\prime} \mathrm{W}, 354 \mathrm{~m}$ MSL) during June, July and August 1976 (Study 76-1: 5-22 June; Study 76-2: 10 July-10 August). The main experimental plot was surrounded by other alfalfa fields. Data presented here were obtained only. during those periods when fetch from the edge of the main field to the two micrometeorological instrumentation locations (Stations 4 and 5) was considered adequate (see Section 3).

Evapotranspiration rate was measured directly with two van Bavel-Myers type precision weighing lysimeters (modified by Rosenberg and Brown, 1970). The lysimeters are equipped with ceramic candle manifolds (bubbling pressure $\sim \frac{1}{3}$ bar) which permits the removal of excess water and helps to maintain a soil moisture profile similar to that in the adjacent undisturbed soil. No visible differences were noted between the alfalfa

\footnotetext{
${ }^{5}$ Warhaft also points out that a necessary condition for $K_{H} / K_{W}$ to be different from unity is that the cross-correlation coefficient of the temperature and humidity fluctuations must be small but this often occurs in the atmospheric boundary layer (e.g., Phelps and Pond, 1971; Thorp et al., 1973).
}

(1976) and soybeans (1970) growing in the lysimeters and growing in the field. Soil moisture conditions, as determined by neutron probe measurements, were similar in both field and lysimeters. The two lysimeters also agreed quite well, generally within $10 \%$. These forms of evidence indicate that the environment of the crop growth in the lysimeters was similar to that in the surrounding field (also discussed in Blad and Rosenberg, 1974). Air temperature and vapor pressure profiles were measured at six elevations in the $2 \mathrm{~m}$ air layer above the canopy with self-checking thermocouple psychrometers described by Rosenberg and Brown (1974). Profiles of wind speed were measured at seven elevations in the $2 \mathrm{~m}$ air layer above the canopy with three-cup lightchopping Casella anemometers [model 442(2)]. Wind direction was measured by means of a wind vane coupled to a variable resistor. Net radiation was measured with two Swissteco net radiometers (type S-1). Soil heat flux was measured with thermal flux plates (designed and produced at the Volcani Institute, Bet Dagan, Israel) buried about $4 \mathrm{~cm}$ deep in the soil.

Temperature, vapor pressure, net radiation and soil heat flux were measured every 7 min during Study 76-1 and every $30 \mathrm{sec}$ during Study 76-2. Wind speed and lysimetric weight change were integrated over $15 \mathrm{~min}$ periods. Data were logged on an automated analog-todigital data recording system. The data were converted from the digital emf or count record of individual sensors into parametric forms with a series of computer programs. All data were averaged over 30 min periods in Study 76-1 and over 15 min periods in Study 76-2.

Measurements of evapotranspiration and microclimate from an irrigated soybean field in 1970 were also used for comparative purposes. Details of that study are given in Blad and Rosenberg (1974).

\section{b. Theoretical details}

The exchange coefficient $K_{W}$ for water vapor was obtained from

$$
K_{W}=\frac{L E_{\perp y s}}{\frac{M_{w} / M_{a}}{P} L_{P}-\frac{\partial e}{\partial z}},
$$




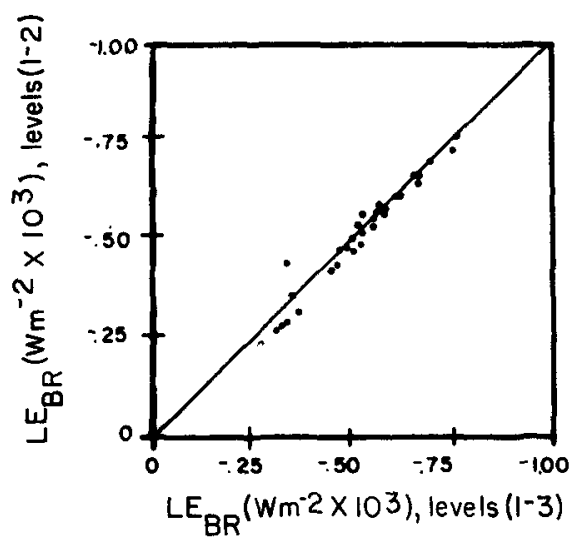

b
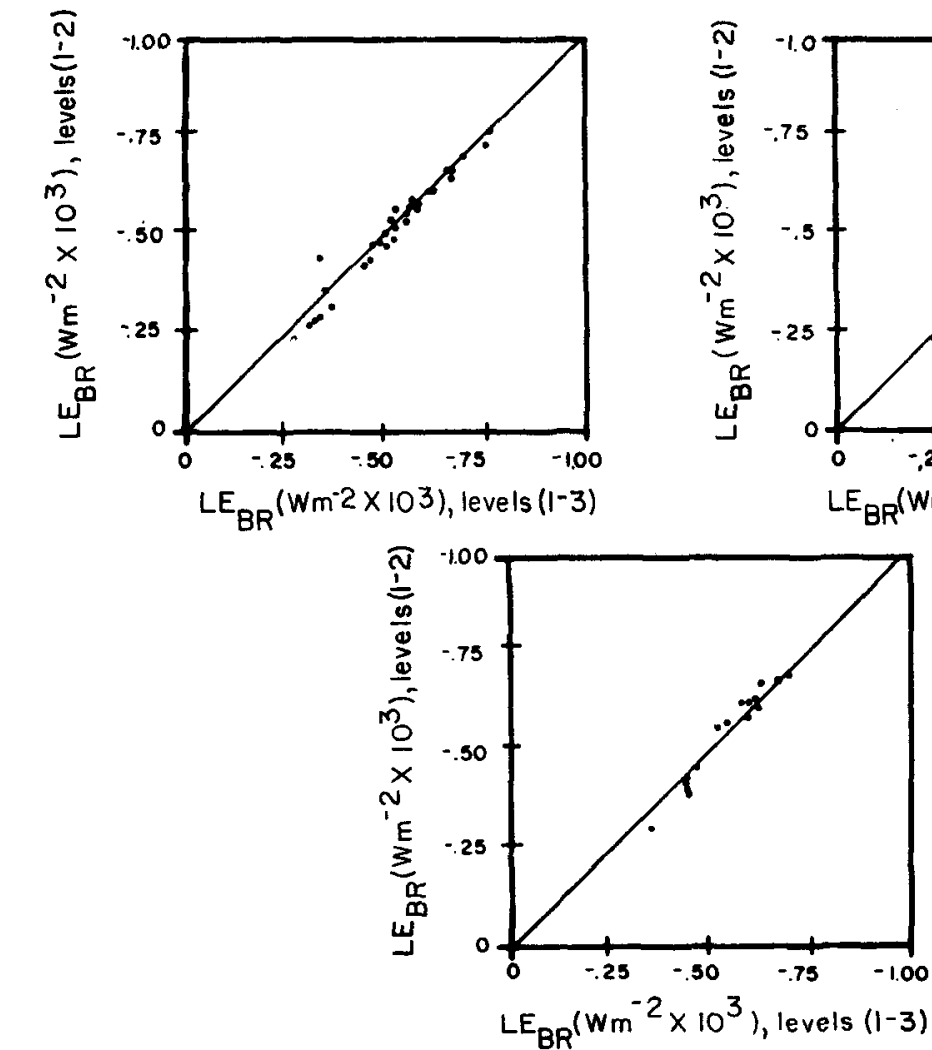

FIG. 3. LE calculated by BREB method for different height intervals: (a) Study 76-1, station 4;

(b) Study 76-1, station 5; (c) Study 76-2, station 5.

where $L E_{\mathrm{Lys}}$ is the lysimetrically measured latent heat flux and $\rho$ is air density. All other terms have been previously defined.

The exchange coefficient $K_{H}$ for sensible heat was obtained from

$$
K_{H}=\frac{A}{\rho c_{p} \frac{\partial T}{\partial z}}=\frac{-\left(R n+L E_{\mathrm{Lys}}+S\right)}{\rho c_{p} \frac{\partial T}{\partial z}}
$$

where the energy balance concept $(R n+L E+S+A=0)$ was utilized to determine sensible heat flux $A$.

The gradients of air temperature $(\partial T / \partial z)$ and vapor pressure $(\partial e / \partial z)$ were computed from air temperature and vapor pressure profiles measured at the three lowest psychrometric levels. Details are given in Table 1 . $L E_{\mathrm{BR}}$ computations were also based on the psychrometric data from the levels indicated in Table 1.

Gradients (or derivatives with respect to height $z$ ) for various profiles of $e, T$ and $U$ were evaluated using finite differences in the manner suggested by Panofsky (1965). If $\Psi$ is a profile variable, then the gradient is given by

$$
\frac{\partial \Psi}{\partial z}=\frac{\Psi_{2}-\Psi_{1}}{\left(z_{1} z_{2}\right)^{\frac{1}{2}} \ln \frac{z_{2}}{z_{1}}},
$$

where $z_{1}$ and $z_{2}$ are heights above the zero plane displacement. This approximation is, of course, rigorous for logarithmic profiles.

\section{Results and discussion}

Values of $K_{H}$ and $K_{W}$ were computed using Eqs. (2) and (3). During Study 76-1 micrometeorological measurements were made at two locations (stations 4 and 5). In each case two different sets of elevations (levels 1-2 and levels 1-3) were used for computation of $\partial T / \partial z$ and $\partial e / \partial z$. Reasonably good agreement between latent heat fluxes $\left(L E_{\mathrm{BR}}\right)$ calculated for levels 1-2 and levels 1-3 (Fig. 3) indicated that the fetch to height ${ }^{6}$ ratio (about 140:1 at station 4 and 200:1 at station 5) was sufficient. ${ }^{7}$ A typical set of air temperature profiles measured on a $16 \mathrm{~m}$ meteorological tower under advective conditions is shown in Fig. 4. The fact that these profiles are inverted up to at least $10-16 \mathrm{~m}$ above ground illustrates that the sensible heat advection phenomenon, reported here, is of a regional rather than local nature.

\footnotetext{
${ }^{6}$ Height above zero plane.

${ }^{7}$ More stringent requirements for fetch to height ratios have been suggested for relatively smooth surfaces. For measurements over crops such as alfalfa and soybeans this requirement can be relaxed.
} 


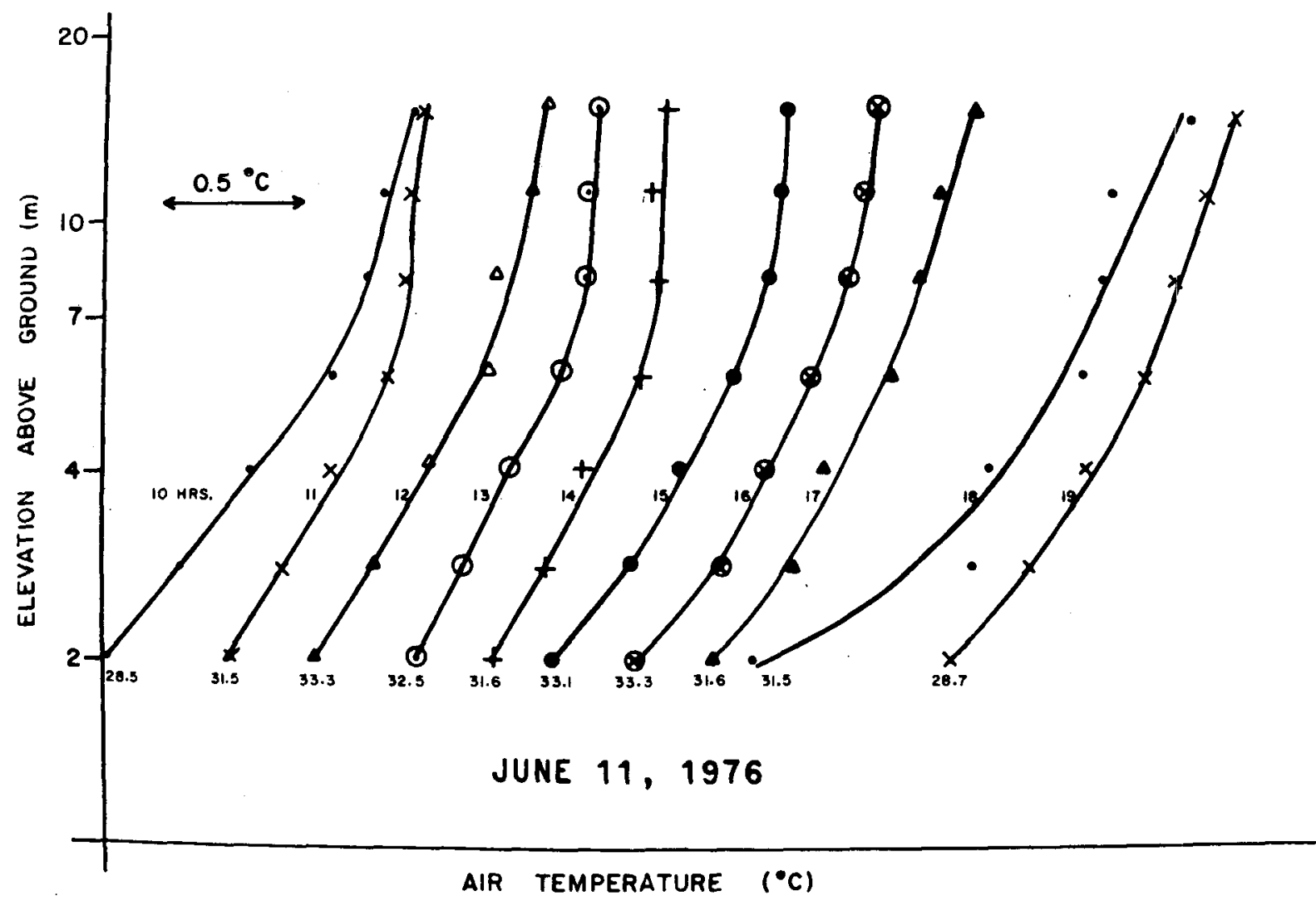

Frg. 4. Progression of air temperature profiles with time of day for 11 June 1976 at Mead, Nebr.
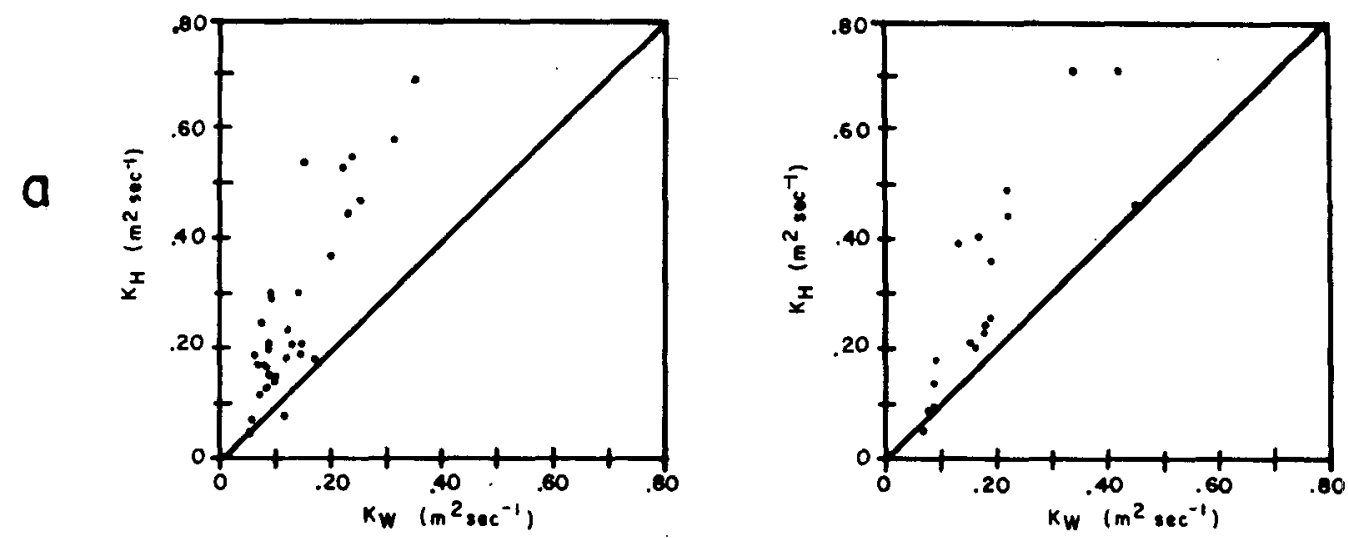

b
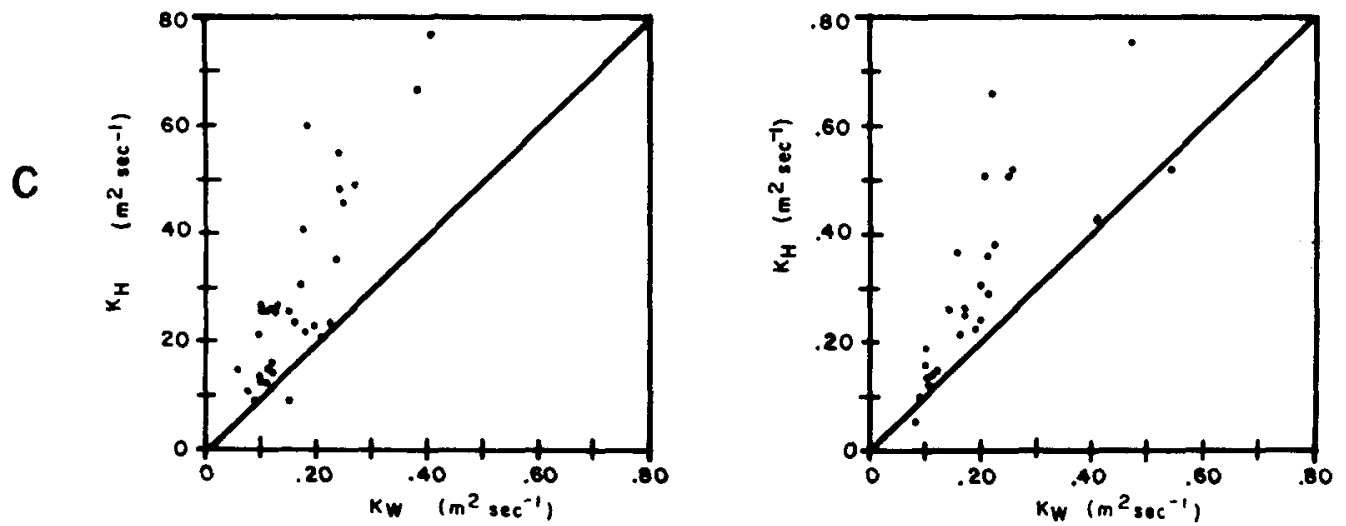

d

FIG. 5. The exchange coefficient for sensible heat $\left(K_{H}\right)$ compared with the exchange coefficient for water vapor $\left(K_{W}\right)$ during Study 76-1 over alfalfa: (a) station 4, levels 1-2; (b) station 5, levels 1-2; (c) station 4, levels 1-3; (d) station 5, levels $1-3$. 
Results obtained in Study 76-1 (Fig. 5) indicate that, under advective conditions, $K_{I}$ values are generally greater than $K_{W}$. Similar results were obtained from measurements over the same crop made during Study 76-2.

Measurements in an irrigated soybean field at Mead during 1970 (26 June-22 July) ${ }^{8}$ were subjected to the same analyses. The relationship between $K_{I I}$ and $K_{W}$ (Fig. 6) is similar to those developed for the 1976 alfalfa crop.

At this point it might be interesting to study the similarity of air temperature and vapor pressure profiles under advective conditions. If we designate by $x$ and $y$ the respective specific concentrations of two quantities which are transported vertically by turbulence, then identity of transfer mechanisms requires that the profiles of $x$ and $y$ be similar (Swinbank and 1)yer, 1967; McVehil, 1962; Webb, 1970). The air temperature and vapor pressure profiles are similar if $(\partial T / \partial z) /(\partial e / \partial z)$ is constant through the constant flux layer. This ratio can be computed for different levels from observed profiles. An index $(I)$ of similarity, therefore, can be defined by

$$
I=\frac{(\Delta T / \Delta e)_{u}}{(\Delta T / \Delta e)_{e}}=\frac{(\Delta T)_{u} /(\Delta T)_{l}}{(\Delta e)_{u} /(\Delta e)_{l}},
$$

where the subscripts $u$ and $e$ refer to an upper and lower layer, respectively, through which the differences can be measured. The index will be equal to 1.0 if the profiles are similar. Typical results of an analysis of air temperature and vapor pressure profile shapes under

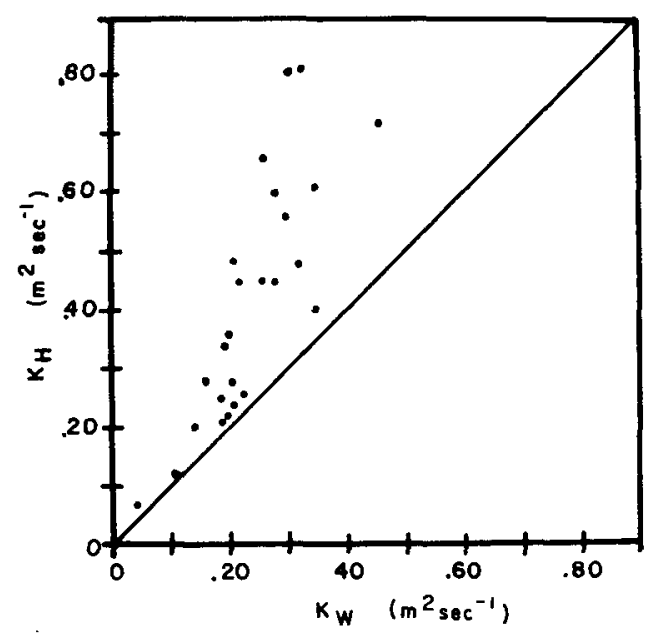

Fig. 6. The exchange coefficient for sensible heat $\left(K_{H}\right)$ compared with the exchange coefficient for water vapor $\left(K_{H}\right)$ during 1970 study over soybeans: $75-100 \mathrm{~cm}$ (26 June-6 July), $125-150 \mathrm{~cm}$ (6-10 July) and 125-150 cm (14-22 July) [see Blad and Rosenberg (1974) for details].

\footnotetext{
${ }^{\mathbf{8}}$ Eqs. (2) and (3) were used with the data reported by Blad and Rosenberg (1974).
}

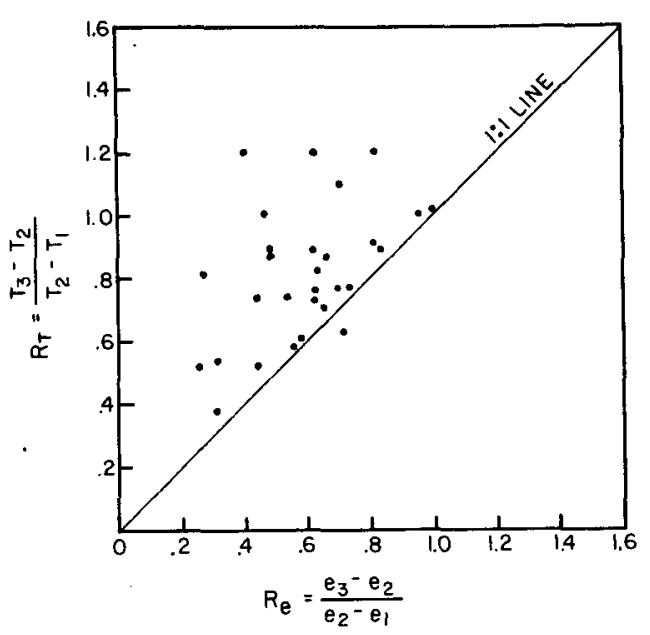

Iir. 7. Ratios of air temperature gradients and vapor pressure gradients under advective conditions for Study 76-1, station 4. Subscripts 1,2 and 3 refer to psychrometric levels defined in Table 1.

conditions of sensible heat advection are presented in Fig. 7 , where $R_{T}=\left(T_{3}-T_{2}\right) /\left(T_{2}-T_{1}\right), R_{c}=\left(e_{3}-e_{2}\right) /$ $\left(e_{2}-e_{1}\right)$, and subscripts 1,2 and 3 refer to psychrometric levels defined in Table 1 . The sy'stematic deviation from similarity between air temperature and vapor pressure profiles under advective conditions is striking.

In order to further elucidate the relationship of $K_{I I}$ and $K_{W}$, the dependence of $K_{I r} / K_{W}$ on a number of variables was studied. These variables are as follows:

1) Gradient Richardson number Ri defined by

$$
\mathrm{Ri}=\frac{g}{T_{v}} \frac{\left(\partial T_{v} / \partial z\right)}{\left(\frac{\partial U}{\partial z}\right)^{2}}
$$

where $g$ is the acceleration due to gravity, and $T_{v}$ and $U$ are the virtual temperature and wind speed at an elevation $z$ above ground.

2) $L E_{\mathrm{Lys}} /(R n+S)$, where $L E_{\mathrm{Lys}}, R z$ and $S$ are flux densities of latent heat (ly sinetrically measured), net radiation and soil heat.

3) $(\partial T / \partial z) /(\partial e / \partial z)=\Delta T / \Delta e \approx T_{2}-T_{1} / e_{2}-e_{1}$, where subscripts 1 and 2 refer to the bottom and top of the air layer being considered.

Fig. 8 shows the ratio $K_{H} / K_{W}$ plotted as a function of $\mathrm{Ri}, L E_{\mathrm{Ly} y} /(R n+S)$ and $\Delta T / \Delta e$ (typical for 1976 studies). Advective conditions are generally accompanied by strong winds, resulting in relatively small $\mathrm{Ri}$ values. Ri has been used in the micrometeorological literature as a good scaling parameter (index of stability) for nonadvective (unstable) and nocturnal inversion (stable) conditions. Under advection-inversion conditions, however, no dependence of $K_{I I} / K_{W}$ on $\mathrm{Ri}$ is apparent. 

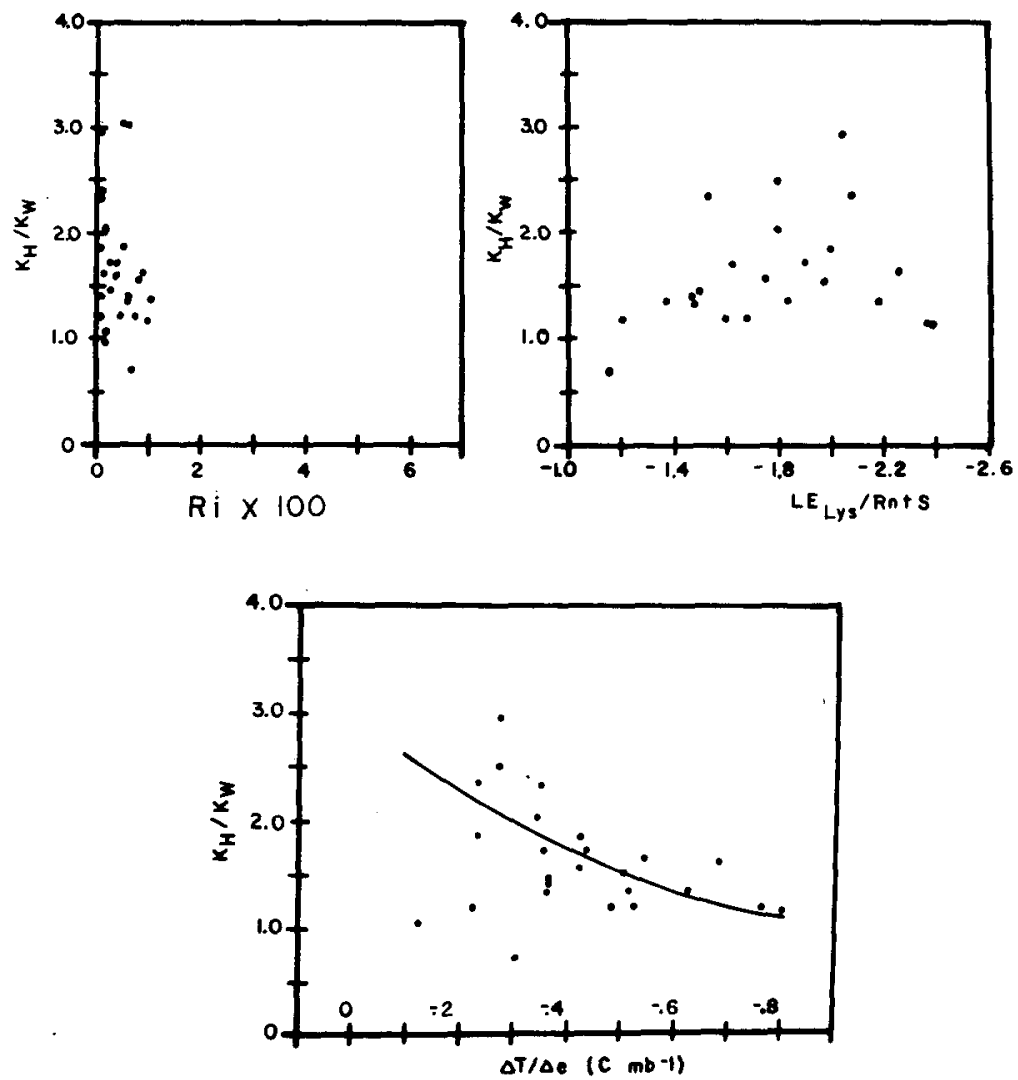

Fig. 8. The ratio of exchange coefficients $K_{H} / K_{W}$ plotted as a function of Richardson number $\mathrm{Ri}, L E_{\mathrm{Lys}} /(R n+S)$ and $\Delta T / \Delta e$ for Study $76-1$ over alfalfa, station 5 , levels $1-3$.

The other independent variables $\left(L E_{\mathrm{Ly}} /(R n+S)\right.$ and $\Delta T / \Delta e$ seem more useful. $L E_{\mathrm{Lys}} /(R n+S)$ will be equal to -1 if the radiant energy available $(R n)$ is consumed primarily in $L E$ and $S$. Under advective conditions additional energy is available from sensible heat and therefore $L E_{\mathrm{Lys}} /(R n+S)<-1$ (or $\mid L E_{\mathrm{Lys}} /$
$(R n+S) \mid>1)$. The quantity $\Delta T / \Delta e$, on the other hand, is a ratio of temperature and vapor pressure gradients and is proportional to the Bowen ratio if $K_{H}=K_{W}$. $\Delta T / \Delta e$ is negative under advective conditions since the transfer of sensible heat and water vapor occurs in opposite directions.
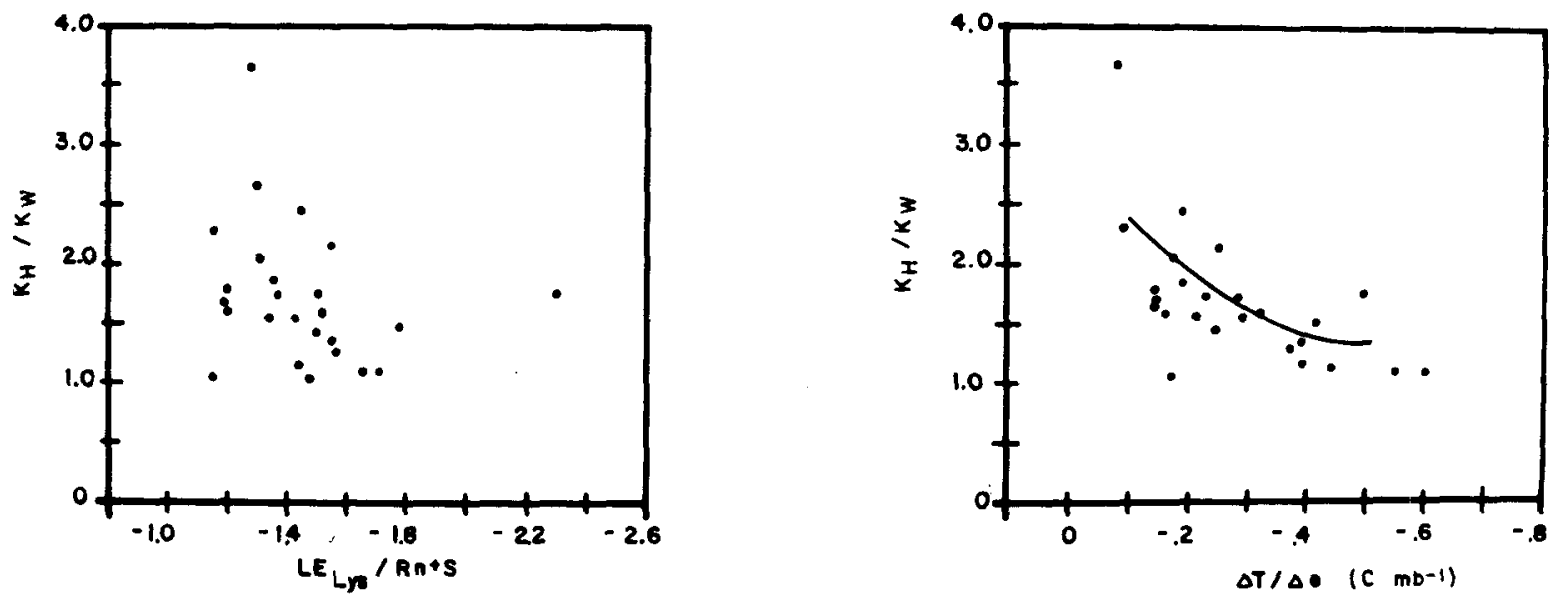

FIG. 9. The ratio of exchange coefficients $K_{H} / K_{W}$ plotted as a function of $L E_{L y_{*}} /(R n+S)$ and $\Delta T / \Delta e$ for 1970 study over soybeans, 75-100 cm (26 June-6 July), 125-150 cm (6-10 July) and 125-150 cm (14-22 July) [see Blad and Rosenberg (1973) for details]. 
TABLE 2. Coefficients for regressions of the ratio of exchange coefficients as functions of $\Delta T / \Delta e$ and $L E_{\mathrm{Lys}} /(R n+S)$. Values of $\Delta T / \Delta e$ are in ${ }^{\circ} \mathrm{C} \mathrm{mb}^{-1}$.

\begin{tabular}{|c|c|c|c|c|c|c|c|c|c|}
\hline \multirow[b]{2}{*}{ Study } & \multirow[b]{2}{*}{$\begin{array}{l}\text { Location and } \\
\text { elevation }\end{array}$} & \multicolumn{4}{|c|}{$\frac{K_{H}}{K_{W}}=A_{0}+A_{1}\left(\frac{\Delta T}{\Delta e}\right)+A_{2}\left(\frac{\Delta T}{\Delta e}\right)^{2 *}$} & \multicolumn{4}{|c|}{$\frac{K_{H}}{K_{W}}=B_{0}+B_{1}\left(\frac{L E_{L y s}}{R n+S}\right)+B_{2}\left(\frac{L E_{\mathrm{Lys}}}{R n+S}\right)^{2}$} \\
\hline & & $A_{0}$ & $A_{1}$ & $A_{2}$ & $\begin{array}{l}\text { Correlation } \\
\text { coefficient } r\end{array}$ & $B_{0}$ & $B_{1}$ & $B_{2}$ & $\begin{array}{l}\text { Correlation } \\
\text { coefficient } r\end{array}$ \\
\hline $76-1$ & $\begin{array}{l}\text { Station } 4, \\
\quad \text { levels } 1-2\end{array}$ & 3.37 & 4.91 & 2.48 & 0.78 & 4.77 & 2.39 & 0.44 & 0.41 \\
\hline $76-1$ & $\begin{array}{l}\text { Station } 4, \\
\quad \text { levels } 1-3\end{array}$ & 2.43 & 1.43 & -.44 & 0.68 & 3.07 & 1.09 & 0.19 & 0.26 \\
\hline $76-1$ & $\begin{array}{l}\text { Station } 5 \\
\quad \text { levels } 1-2\end{array}$ & 3.47 & 5.96 & 3.75 & 0.65 & 0.10 & -1.63 & -0.38 & 0.22 \\
\hline $76-1$ & $\begin{array}{l}\text { Station } 5, \\
\quad \text { levels } 1-3\end{array}$ & 2.51 & 2.57 & 1.09 & 0.56 & -0.52 & -2.10 & -0.48 & 0.39 \\
\hline $76-2$ & $\begin{array}{l}\text { Station } 5 \text {, } \\
\quad \text { levels } 1-2\end{array}$ & 2.61 & 3.51 & 1.90 & 0.68 & 0.64 & -0.96 & -0.27 & 0.35 \\
\hline $76-2$ & $\begin{array}{l}\text { Station } 5 \\
\quad \text { levels } 1-3\end{array}$ & 2.69 & 3.50 & 1.64 & 0.76 & 1.86 & 0.16 & -0.05 & 0.36 \\
\hline $1970^{*}$ & & 2.99 & 6.66 & 6.71 & 0.61 & 3.68 & 2.15 & 0.56 & 0.20 \\
\hline
\end{tabular}

* See Blad and Rosenberg (1974) for details.

Typical plots of $K_{H} / K_{W}$ vs $L E_{\mathrm{Lys}} /(R n+S)$ and vs $\Delta T / \Delta e$ for the 1970 study over soybeans are presented in Fig. 9. There occurs a significant scatter in plots of $K_{H} / K_{W}$ vs $L E_{\mathrm{Lys}} /(R n+S$ ) (Figs. 8 and 9 ) and no distinct relationship is apparent. Even though there is some scatter in $K_{H} / K_{W}$ vs $\Delta T / \Delta e$ plots, $K_{H} / K_{W}$ values appear much better correlated with $\Delta T / \Delta e$ [see Table 2 for correlation coefficients obtained from the regression of $K_{H} / K_{W}$ data on $\Delta T / \Delta e$ and $\left.L E_{\mathrm{Lys}} /(R n+S)\right]$.

The ratio $K_{H} / K_{W}$ is plotted as a function of $\Delta T / \Delta e$ and $L E_{\mathrm{Ly}_{\mathrm{s}}}$ in Fig. 10. It appears that high $L E$ values are associated with the lower $|\Delta T / \Delta e|$ values. This in turn indicates that low $|\Delta T / \Delta e|$ values may be associated with strongly advective conditions. A detailed interpretation of the significance of $\Delta T / \Delta e$ values is not yet ready.

The regressions of $K_{H} / K_{W}$ on $\Delta T / \Delta e$ for each of the

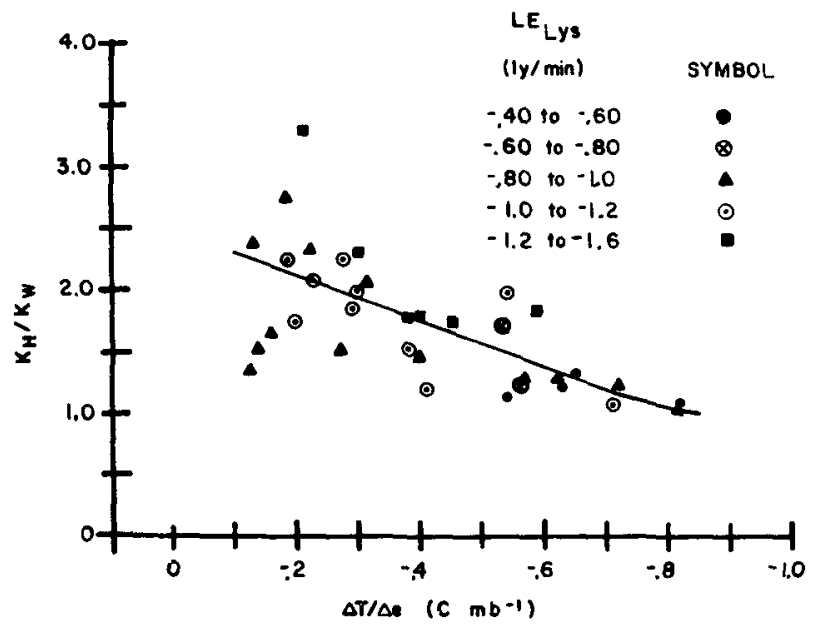

FIG. 10. $K_{H} / K_{W}$ plotted as a function of $\Delta T / \Delta e$ and $L E_{\text {Lys }}$ for Study 76-1, station 4 , levels $1-3$. three studies are plotted in Fig. 11. Reasonably good agreement in the nature of these relationships is found for all of the three studies (76-1 and 76-2 over alfalfa and the 1970 study over soybeans).

\section{Summary and conclusions}

Micrometeorological measurements made over alfalfa and soybeans have shown that, under advective conditions, the exchange coefficient for sensible heat is generally greater than the exchange coefficient for water vapor. This result is at variance with the time-honored assumption of equality between $K_{H}$ and $K_{W}$. Indeed it has been well-established that $K_{H}$ and $K_{W}$ are normally equal under nonadvective (lapse or unstable) conditions when both sensible heat and water vapor are trans-

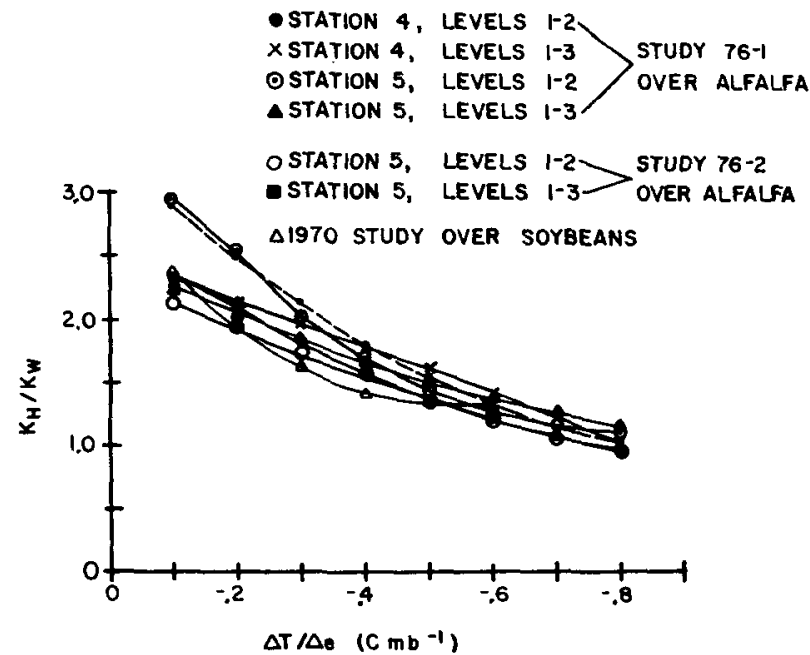

Fig. 11. The regressions $K_{H} / K_{W}$ on $\Delta T / \Delta e$ for Studies 76-1 and $76-2$ over alfalfa and for 1970 study over soybeans. 
ferred away from the earth's surface. Under advective conditions, however, heat and water vapor are transferred in opposite directions. Recent theoretical analysis by Warhaft (1976) indicates that such a situation is one under which large departures of $K_{H} / K_{W}$ from unity will occur. The data presented here and Warhaft's newly available theory support our contention that $K_{H} \neq K_{W}$ under conditions of sensible heat advection.

This nonequality of exchange coefficients is particularly significant with respect to the Bowen ratio-energy balance method of evapotranspiration estimation, which is based upon the assumption that $K_{I I}=K_{W}$. Use of this assumption results in a consistent underestimation of evapotranspiration rates under advective conditions.

Values of $K_{H} / K_{W}$ appear to be well correlated with $(\Delta T / \Delta e)$, the ratio of temperature and vapor pressure gradients. Regression equations, relating $K_{I I} / K_{W}$ to $\Delta T / \Delta e$, obtained for 1976 studies over alfalfa, compared favorably with the equation fitted to data from a 1970 study over soybeans. In a forthcoming paper these $K_{H} / K_{W}$ relationships will be incorporated into the Bowen ratio equation to make its use under advective conditions more effective.

Acknowledgments. This study was conducted with support of the Atmospheric Sciences Section, National Science Foundation, under Grant DES-10000 A01. Our thanks to Messrs. Dale E. Sandin, Thomas Keber, James Hines, Raymond Motha, Thomas Brakke and Silvio Steinmetz who assisted in the field observation and data computation, to Mrs. Roberta Sandhorst for stenographic work, to Mrs. Susan Cannon and Mr. Bruce Sandhorst for drafting, and to Drs. Albert Weiss and James Gilley for their review of this paper.

\section{REFERENCES}

Blad, B. L., and N. J. Rosenberg, 1974: Lysimetric calibration of the Bowen ratio-energy balance method for evapotranspiration estimation in the central Great Plains. J. Appl. Meleor., $13,227-236$.

Denmead, O. T., and I. C. McIlroy, 1970: Measurements of nonpotential evaporation from wheat. Agric. Meteor., 7, 285-302.
Dyer, A. J., 1963: The adjustment of proliles and eddy fluxes. Quart. J. Roy. Meleor. Soc., 89, 276-280.

McIlroy, I. C., and D. E. Angus, 1964: (irass, water and soil evaporation at Aspendale. $A$ gric. Meleor., 1, 201-224.

McVehil, G. L., Jr., 1962: Wind distribution in the diabatic boundary layer. Ph.1. thesis, Pennsylvania State University.

Oke, T. R., 1970: Turbulent transport near the ground in stable conditions. J. Appl. Meteor., 9, 778-786.

Panofsky, H. A., 1965: Reanalysis of Swinbank's Kerang observations. Flux of heat and momentum in the planetary boundary layer. Dept. of Meteorology, Rep., Pennsylvania State University, pp. 67-76.

Phèjps, G. T., and S. Pond, 1971 : Spectra of the temperature and humidity fluctuations and of the fluxes of moisture and sensible heat in the marine boundary layer. J. Atmos. Sci., 28, 918-928.

Philip, J. R., 1959: The theory of local advection: I. J. Meteor., $16,535-547$.

Pruitt, W. O., and F. J. Lourence, 1968: Correlation of climatological data with water requirements of crolys. 1966-1968 Rep., Dept. of Water Science and Engineering, University of California, Davis, $59 \mathrm{pp}$.

Rao, K. S., J. C. Wyngaard and O. R. Cote, 1974: Local advection of momentum, heat, and moisture in micrometeorology. Bound.-Layer Meteor., 7, 331-348.

Rider, N. E., J. R. Philip and E. F. Bradley, 1963: The horizontal transport of heat and moisture--a micrometeorological study. Quart. J. Roy. Meteor. Soc., 89, 507-530; and discussions, 90, 236-240 (1964).

Rosenberg, N. J., 1969 : Seasonal patterns in evapotranspiration by irrigated alfalfa in the central Great Plains. Agron. J., 61, 879-886.

- , and K. W. Brown, 1970: Improvements in the Van BavelMyers automatic weighing lysimeter. Water Resour. Res., 6, $1227-1229$.

_-, and -_, 1974: "Self checking" psychrometer system for gradient and profile determinations near the ground. Agric. Meleor., 13, 215-226.

Swinbank, W. C., and A. J. Dyer, 1967 : An experimental study in micrometeorology. Quari. J. Roy. Meteor. Soc., 93, 494-500.

Sutton, O. G., 1953: Micrometeorology. McGraw Hill, 333 pp.

Tanner, C. B., 1960: Energy balance approach to evapotranspiration from crops. Soil Sci. Soc. Amer. Proc., 24, 1-9.

Thorpe, M. R., E. G. Banke and S. D. Smith, 1973: Eddy correlation measurements of evaporation and sensible heat fux over arctic sea ice. J. Geophys. Res., 78, 3573--3584.

Warhaft, Z., 1976: Heat and moisture flux in the stratified boundary layer. Quart. J. Roy. Meteor. Soc., 102, 703-704.

Webb, E. K., 1970 : Profile relationships: the log-linear range, and extension to strong stability. Quart. J. Roy. Meteor. Soc., 96, $67-90$. 